\title{
Acromegaly is protective for periodontal tissue - advanced chronic periodontitis is rare in acromegalics
}

\author{
Bascil $\mathrm{S}^{1}$, Serinsoz $\mathrm{H}^{2}$, Tutuncu $\mathrm{NB}^{2}$ \\ Baskent University Faculty of Dentistry, Department of Periodontology, Adana, Turkey. \\ neslibascil@yahoo.com
}

\begin{abstract}
Background: Acromegaly is a complex syndrome which influences the connective tissue and bone metabolism. Although the effects of excess growth hormone on bone tissue are well known, its effect on periodontal tissue is an enigma.

Methods: A total of 23 acromegalic patients (mean age $48.13 \pm 9.4$ years) were included randomly in to this cross-sectional study. The control group consisted of 60 healthy (mean age $50.3 \pm 8.5$ ) individuals. All participants were examined by the same periodontist to evaluate periodontal disease status.

Results: We studied a group of 23 acromegalic patients (11 females, 12 males) with estimated duration of disease from minimum of one year to 10 years (mean $4.52 \pm 2.9$ years). The frequency of advanced chronic periodontitis in acromegalics was significantly lower than in the healthy group $(p=0.002)$. Advanced periodontitis was 10 times more frequent in healthy population than in the acromegalics.

Conclusions: Advanced chronic periodontitis is 10 times less frequent in acromegalics than in healthy population. Acromegaly is a disease which seems to be protective for periodontal tissue (Tab. 4, Ref. 30). Text in PDF www.elis.sk.

Key words: acromegaly, chronic periodontitis, IGF-1, growth hormone.
\end{abstract}

Acromegaly is a rare disease characterised by uncontrolled secretion of growth hormone $(\mathrm{GH})$ from the hypophysis. It is usually asymptomatic unless it reaches $10 \mathrm{~mm}$ in size. In the advanced stage, it has typical oral features of prognathism, macroglossia, increased interdental spaces and dental mobility as well as the systemic features of enlarged hands and feet, bulging of the frontal bone, cardiovascular diseases, osteoarthritis and sleep apnea (1). Although its typical characteristics are well known, little is known about the periodontal status of these patients in different stages of the disease.

Acromegalic patients have increased $\mathrm{GH}$, insulin like growth factor-1 (IGF-1), insulin like growth factor binding protein-3 and calcitriol levels. These directly affect the bone cells and connective tissue. Likewise, coexistence of hypogonadism, thyroid hormone imbalance and glucose intolerance may all have an impact on the periodontal tissue and bone. In this complicated network of influencing factors it is hard to define a specific periodontal disease for acromegalic patients (2-9).

In the periodontal tissue direct and indirect effects of GH/IGF-1 system is not well known but it is a hot topic in the field of orthodontics and implantation. Osteoblasts are the leading cells in bone

${ }^{1}$ Baskent University Faculty of Dentistry, Department of Periodontology, Adana, Turkey, and ${ }^{2}$ Baskent University Faculty of Medicine, Department of Endocrinology and Metabolism, Adana, Turkey

Address for correspondence: N.B. Tutuncu, MD, Baskent Universitesi Faculty of Medicine, Department of Endocrinology and Metabolism, Bahcelievler 5. sokak, Ankara, Turkey.

Phone: +90.312.2126701, Fax: +90.312.2129717 which regulate bone dynamics by timing bone remodelling under different influences. Likewise human periodontal ligament (PDL) cells behave like osteoblasts and are the master cells in periodontal tissue regulating connective tissue resorption or synthesis in different clinical situations. PDL cells are different from gingival fibroblasts in that they proliferate at a higher rate and show higher levels of cAMP production and greater ALP-ase activity (10-11). Kanzaki $\mathrm{H}$ and friends discovered that PDL cells not only support osteoclasts genesis through cell-to-cell contact, but also inhibit the formation of tartrate-resistant acid phosphatase-positive multinucleated cells by producing soluble factor(s) (12). Furthermore, PDL cells express both receptor activator of nuclear factor kappa B ligand and osteoprotegerin messenger RNA, like osteoblasts. They were shown to modulate osteoclastogenesis in different situations like mechanical stress and inflammation (13-14).

In light of these studies we hypothesized an anabolic state of periodontal matrix as a consequence of excess GH/IGF-1 in acromegalics. In our study we aimed to explore the periodontal tissue involvement in the clinical presentation of acromegaly and compare it with the healthy age and sex matched volunteers.

\section{Materials and methods}

A total of 23 acromegalic patients (mean age $48.13 \pm 9.4$ years) were included randomly into this cross-sectional study. Patients with the diagnosis of acromegaly were selected randomly from the outpatient clinic of the Endocrinology Department at Baskent University, Faculty of Medicine, during routine periodic control 
visits. The following variables were specifically recorded: age, body mass index, duration of the disease, history of pituitary surgery and radiotherapy, activity of the disease, IGF-1 and IGFBP-3 levels, treatment with a sandostatin analogue, length of remission, evaluation of anterior hypophysis hormonal reserve, renal and liver function tests. Exclusion criteria involved the other conditions known to influence the periodontal tissue and bone by causing osteopenia. These were chronic renal failure, hyperthyroidism or hyperparathyroidism and active smoking. The control group consisted of 60 healthy individuals (mean age $50.3 \pm 8.5$ ) who were randomly selected from relatives or friends of the hospital staff with similar age and social economic status. Patients were systemically healthy, had not received anti-inflammatory agents, antibiotics or immunosuppressants in the past 6 months, and had never smoked.

All acromegalic patients and individuals in the control group were examined by the same experienced periodontist. Periodontal pocket depth (presence of an abnormal gingival sulcus near the point at which the gums contact tooth) was evaluated using periodontal probe at six different points of each tooth. Individuals with probing pocket depth (PPD) between 4-6 mm and clinical attachment level $(\mathrm{CAL}=$ amount of space between attached periodontal tissues and a fixed point, usually the cementoenamel junction) up to $4 \mathrm{~mm}$ as having chronic periodontitis with slight to moderate loss of periodontal support (15). Those with PPD $\geq 6 \mathrm{~mm}$ and CAL greater than $4 \mathrm{~mm}$ were diagnosed as having chronic periodontitis with advanced loss of periodontal support (16).

Bleeding on probing which was considered an objective inflammatory parameter in periodontitis establishment, was measured using gingival bleeding index (GBI) (17). Gingival bleeding index $\leq 0.1$ was considered as low risk for the development of periodontitis. Tooth mobility levels were evaluated and classified (18) as degrees 1, 2, and 3. Radiographic examinations, tooth loss, diastemas (space or gap between two teeth) and malocclusion were also assessed.

Individuals from both groups were asked to fill a questionnaire about oral hygiene and frequency of dentist visits till today.
Patientslinical data were evaluated and assessed by the same experienced endocrinologist.

The diagnosis of acromegaly was established clinically and confirmed by high serum GH concentrations that were not suppressed after oral glucose tolerance test ( $75 \mathrm{~g}$ ), elevated IGF-1 levels for age and sex and demonstration of the pituitary tumor by computed tomographic scan or magnetic resonance imaging. The estimated duration of the disease was determined according to the clinical history and review of the past photographs of the patients. The disease activity was assessed by GH suppression during OGTT. Hormonal status of anterior hypophysis was analysed by both basal serum pituitary hormone levels (ACTH, PRL, FSH, LH, $\mathrm{TSH})$ with their end organ hormones and dynamic tests $(19,20)$.

All ethical aspects were rigidly observed, the study was conducted only after its approval by the local ethics committee. All patients gave informed consent to participate in this study in accordance with Helsinki declaration.

Serum levels of GH, IGF-1 and IGFBP-3 were determined by commercially available kits: chemiluminescent enzyme immunometric assay for GH (Immulite Growth Hormone, Diagnostic Products Corp., CA, USA); immunoradiometric assay (Diagnostic Systems Laboratories, DSL-6600 ACTIVE) for IGFBP-3; highly sensitive and specific immunoradiometric assay which uses modified form of the standard acid-ethanol extraction procedure (Diagnostic Systems Laboratories, DSL-5600 ACTIVE) for plasma IGF-1.

Descriptive statistical values for the study group are expressed as mean \pm standard deviation for continuous variables and as proportions for ordinal (categorical) variables, such as gender, smoking, radiotherapy, operations or presence of hypogonadism, periodontitis and malocclusion. Differences within patient clinical characteristics and comparisons with the healthy control group were assessed for statistical significance using the Student's $\mathrm{t}$ test and the Chi-square, where appropriate. Correlations between acromegaly disease duration, disease activity status and oral pathologies in the acromegalic patients were tested using Pearson

Tab. 1. Clinical characteristics of the acromegalics and control group.

\begin{tabular}{|c|c|c|c|}
\hline & Acromegaly Patients & Healthy Control Group & $\mathrm{p}$ \\
\hline $\mathrm{n}$ & 23 & 60 & - \\
\hline Age (years) & $48.13 \pm 9.4$ & $50.32 \pm 8.5$ & NS \\
\hline Sex (F/M) & $11 / 12$ & $34 / 26$ & NS \\
\hline Duration of acromegaly (years) & $4.52 \pm 2.9$ & - & NS \\
\hline Acromegaly- cured & $1 / 23$ & - & - \\
\hline Acromegaly-inactive with medication & $10 / 23$ & - & - \\
\hline Acromegaly-active & $12 / 23$ & - & - \\
\hline Chronic Periodontitis & $12 / 23(52.2 \%)$ & $40 / 60(66.7 \%)$ & NS \\
\hline Slight-moderate chronic periodontitis & $11 / 23(47.8 \%)$ & $14 / 60(23.3 \%)$ & NS \\
\hline Advanced chronic periodontitis & $1 / 23(4.3 \%)$ & $26 / 60(43.3 \%)$ & 0.002 \\
\hline No periodontal pathology & $11 / 23(47.8 \%)$ & $20 / 60(33.3 \%)$ & NS \\
\hline Macroglossia & $9 / 23(39.1 \%)$ & 0 & 0.0001 \\
\hline Hypogonadism & $6 / 23(26.1 \%)$ & 0 & 0.0001 \\
\hline Past-smoker & $2 / 23(8.7 \%)$ & 0 & 0.0001 \\
\hline
\end{tabular}

NS = nonsignificant 
Tab. 2. Clinical characteristics of acromegalic patients.

\begin{tabular}{lc}
\hline & $\mathrm{n}(\%)$ \\
\hline Total acromegaly patients & 23 \\
\hline Acromegaly- cured & $1(4.3)$ \\
\hline Acromegaly-inactive with medication & $10(43)$ \\
\hline Acromegaly-active & $12(52.2)$ \\
\hline Macroglossia & $9(39.1)$ \\
\hline Hypogonadism & $6(26.1)$ \\
\hline Past-smoker & $2(8.7)$ \\
\hline Disorder of Glucose Metabolism & $13(56.5)$ \\
\hline Pituitary surgey & $12(52.2)$ \\
\hline Radiotherapy & $3(13.0)$ \\
\hline Somatostatin analogs & $23(100)$
\end{tabular}

correlation. Statistical significance was considered when a twosided $\mathrm{p}$ value was 0.05 or below. The statistical software PASW was used for statistical analysis.

\section{Results}

We studied a group of 23 patients ( 11 females, 12 males) with estimated duration of the disease from minimum of one year to 10 years (mean $4.52 \pm 2.9$ years). There were two past smokers in the acromegaly patient group and none in the healthy control group. These 2 patients smoked up to 5 and 10 cigars per day for 4 years and 7 years, respectively. They both quit smoking more than 5 years ago. There were 6 patients diagnosed with hypogonadism after surgery and they received hormonal replacement. Patients with hypogonadism did not have lumbar and femoral osteoporosis. Among the acromegalics, 13 had glucose intolerance among which 6 received oral drugs and others were treated with diabetic diet. Clinical characteristics of acromegalic patients and the control group are shown in Table 1.

Twelve patients had been submitted to pituitary surgery and 3 patients had radiotherapy. Somatostatin analogue, either Octreotide or Lanreotide was given to all 23 patients to control GH secretion at the hypophyseal level. Disease cure was defined when all these criteria were met: random GH level less than $2.5 \mathrm{mg} / \mathrm{L}$ and plasma IGF-1 levels normal for age and GH suppressed during OGTT and the patient is not taking any sandostatin analogue. There was only one patient in whom the disease was cured. Disease was defined as inactive when random $\mathrm{GH}$ level was less than $2.5 \mu \mathrm{g} / \mathrm{L}$ and plasma IGF-1 levels were normal for age under a sandostatin analogue. There were 10 patients with inactive disease. Those having high $\mathrm{GH}$ and or IGF-1 levels had active, uncontrolled disease $(\mathrm{n}=12)$. There were 6 patients with hypogonadism and 13 patients with a disorder of glucose metabolism (Tab. 2). The duration of acromegaly was found to be negatively correlated with hypophyseal disease activity $(p=0.01)$. More patients had controlled disease as the duration from the time of diagnosis increased.

Our study revealed significantly lower frequency of advanced chronic periodontitis in the acromegalics compared to the healthy group $(\mathrm{p}=0.002)$. About $43.3 \%(26 / 60)$ of the healthy group and $4.3 \%(1 / 23)$ of the acromegalics had advanced chronic periodontitis. That is advanced periodontitis was 10 times more frequent in healthy population than in the acromegalics. Among the acromegalics about $47.8 \%$ of them had healthy periodontal tissue while this rate was about $33.3 \%$ in the healthy population. Clinical periodontal disease status of the acromegalics and healthy volunteers is shown in Table 3.

Among the acromegalics those with active disease (high plasma GH and/or IGF-1 levels) showed significantly increased frequency of chronic periodontitis (slight-to-moderate and advanced) compared to those with inactive or cured disease (normal plasma $\mathrm{GH}$ and/or IGF-1 levels) $(\mathrm{p}=0.011)$ (Tab. 4). Inactive disease duration (length of remission) was found to be negatively correlated with chronic periodontitis of any degree $(p=0.030)$. As the time period of normal/near normal plasma GH/IGF-1 level increased (control of acromegaly or length of remission) patients encountered with chronic periodontitis decreased. Also the degree of chronic periodontitis (slight-to-moderate or advanced) was found to be positively correlated with activity of acromegaly $(p=0.043)$. Frequency of smokers, glucose intolerance, macroglossia and hypogonadism were similar in acromegalics with and without active disease.

\section{Discussion}

Periodontal disease is an infection driven chronic inflammatory disease characterized by resorption of tooth-supporting alveolar bone. The etiology of this disease is complex and multifactorial involving both genetic and environmental factors. Although up to $50 \%$ of periodontitis susceptibility is credited to hereditary factors in oral tolerance and regulation of mucosal immunity based on

Tab. 4. Chronic periodontitis cases in acromegalics.

\begin{tabular}{l|c|c}
\hline & $\mathrm{n}$ & $\begin{array}{c}\text { Chronic periodontitis } \\
\text { cases (n) }\end{array}$ \\
\hline Acromegalic patients/Disease active & 12 & 10 \\
\hline Acromegalic patients/Disease cured or inactive & 11 & 3 \\
\hline $\mathrm{p}$ & $\mathrm{NS}$ & 0.011 \\
\hline $\mathrm{NS}=$ nonsignificant & \multicolumn{3}{|l}{}
\end{tabular}

Tab. 3. clinical periodontal status of the acromegalic patients and the healthy controls.

\begin{tabular}{lccc}
\hline & $\begin{array}{c}\text { Acromegalics with } \\
\text { periodontitis }\end{array}$ & $\begin{array}{c}\text { Acromegalics without } \\
\text { periodontitis }\end{array}$ & $\begin{array}{c}\text { Healthy controls with } \\
\text { periodontitis }\end{array}$ \\
\hline GBI & $1.86 \pm 0.34$ & $0.75 \pm 0.56$ & $1.92 \pm 0.72$ \\
\hline PPD & $4.60 \pm 1.00$ & $2.23 \pm 0.87$ & $5.12 \pm 0.54$ \\
\hline CAL & $3.88 \pm 1.30$ & $0.39 \pm 1.29$ & $4.01 \pm 1.24$ \\
\hline PI & $1.90 \pm 0.46$ & $1.28 \pm 0.44$ & $2.1 \pm 0.62$ \\
\hline
\end{tabular}

$\mathrm{GBI}=$ gingival bleeding index; $\mathrm{PPD}=$ periodontal probing depth $\mathrm{CAL}=$ clinical attachment loss; $\mathrm{PI}=$ plaque index 
family studies, twin studies, and population studies, environmental factors are very important in most populations and disease states.

In the present study, evaluation of periodontal status of 23 acromegalic patients revealed that advanced chronic periodontitis is encountered less frequently in acromegalics compared to healthy population. Interestingly, in our study population healthy volunteers revealed chronic periodontitis more often than the acromegalics. Our findings demonstrate that two of three $(66.7 \%)$ otherwise healthy Turkish people have some degree of chronic periodontitis. Similar to our findings, prevalence of chronic periodontitis was found to be $40-70 \%$ in other studies of otherwise healthy Turkish population. Due to this high prevalence of periodontitis, Saydam $\mathrm{G}$. and friends underlined the importance of preventive periodontal therapy and community-based prophylaxis methods for future nationwide dental health service planning in Turkey (21-24).

Although GH excess has complex consequences on bone and connective tissue metabolism there is yet very few data about periodontal pathologies in these patients (25-27). As long as our English literature search is concerned, we could find only one study evaluating the periodontal status in acromegalics. In accordance with our findings, in the study of Lima et al, they found no periodontitis in 16 acromegalics despite the presence of diabetes mellitus (28). There are many hormones effecting periodontal tissue including the sex hormones, parathyroid and thyroid hormones and GH. Osteoblasts have GH receptors and after stimulation by this hormone they increase matrix formation. It also has indirect actions via IGF-1 which via autocrine and paracrine effects is anabolic for bone (21). In recent years, it is postulated that IGF-1 has impact on periodontal ligament fibroblasts and has protective effect for periodontitis in acromegalic patients. In this regard GH has been used to improve dental peri-implant bone tissue. Likewise, several reports have documented that in adults with isolated $\mathrm{GH}$ deficiency, which is an opposite clinical situation with acromegaly, chance of having periodontal attachment loss (PAL) is increased compared to healthy individuals $(28,30)$.

In search for the integrating situations affecting the periodontal tissue in acromegalics we analysed the hormonal status, smoking habits and glucose metabolism of the patients in our study. Interestingly, we found no association with the gonadal and glycemia status nor the treatment strategies including surgery, radiotherapy and sandostatin analogue therapy with the periodontal well-being. Having dysglycemia $(n=13)$, history of hypogonadism $(n=6)$ and smoking $(\mathrm{n}=2)$ in acromegalic group did not end up with more severe oral periodontal disease status compared with the controls.

It was surprising to find out that although acromegaly is a disease which seems to be protective for periodontal tissue, disease activity had negative impact. We found that chronic periodontitis was more often encountered in acromegalic patients with active disease, that is those having high GH/IGF-1 levels at that time point. In parallel with this finding, we also found that among the acromegalics with longer duration of disease control (with low GH/IGF-1 levels), fewer periodontitis cases and periodontitis with lesser degrees were diagnosed. This may be due to a statistical bias because of the small number of acromegalic patients in our study or inadequate evaluation of confounding factors affecting the periodontal tissue. This may also be a consequence of longer cumulative GH/IGF-1 excess in those with longer duration of acromegaly. In our study, those acromegalics with longer remission period with controlled hormone levels also have longer acromegaly duration. It was interesting to note that among the acromegalics we studied, there was only one case with advanced chronic periodontitis in whom acromegaly was diagnosed very recently, and thus the disease was not controlled yet. In this index case cumulative amount of excess GH/IGF-1 is expected to be small as the disease was diagnosed recently.

In our opinion, the cumulative amount of excess GH/IGF-1 exposure may be the main protective factor for periodontal tissue. Detailed analysis in a prospectively designed clinical trial with periodic measurements of plasma GH/IGF-1 levels from the time of diagnosis of acromegaly would give more clear data about the role of GH/IGF-1 system on periodontal tissue.

Importantly, possible major bias is the fact that patients with acromegaly may be more likely to visit a dentist due to their teeth problems therefore have better dental care. In fact, for our acromegaly patients, this was not the case according to the questionnaire answered about oral hygiene and past dentist visits.

We are aware of the possible selection bias both in acromegalics and control subjects which may not truly reflect what is happening in real life and does not allow to conclude that acromegaly is protective for periodontal disease. Keeping in mind this and that acromegaly is a very rare disease with a prevalence of 50-70 cases per million persons, it is usually hard to evaluate large numbers of cases in a single centre. We conclude that acromegaly is a disease with possible protective effects on the periodontal tissue. This very early conclusion is drawn from our preliminary study and from that of Lima et al. Among the very few studies evaluating oral pathologies and especially the periodontal tissue in acromegalics, our study forms the basis for future studies with larger groups of patients aimed to find out the chronic periodontitis frequency and factors influencing periodontal tissue in these patients.

\section{References}

1. Barkan AL. Acromegaly. Diagnosis and therapy. Endocrinol Metab Clin North Am 1989; 18: 277-310.

2. Diamond T, Nery L, Posen S. Spinal and peripheral bone mineral densities in acromegaly: the effects of excess growth hormone and hypogonadism. Ann Intern Med 1989; 111: 567-573.

3. Ezzat S, Melmed S, Endres D, Eyre DR, Singer FR. Biochemical assessment of bone formation and resorption in acromegaly. J Clin Endocrinol Metab 1993; 76: 1452-1457.

4. Fredstorp L, Pernow Y, Werner S. The short and long term effects of octreotide on calcium homeostasis in patients with acromegaly. Clin Endocrinol 1993; 39: 331-336.

5. Kayath MJ, Vieira JGH. Osteopenia occurs in a minority of patients with acromegaly and is predominant in the spine. Osteoporosis Int 1997; 7: $226-230$.

6. Lesse GP, Fraser WD, Farquharson R, Hipkin L, Vora JP. Gonadal status is an important determinant of bone density in acromegaly. Clin Endocrinol 1998; 48: 59-65. 


\section{8-592}

7. Ohlsson C, Bengtsson B, Isaksson OGP, Andreassen TT, Slootweg MC. Growth hormone and bone. Endocr Rev 1998; 1: 55-79.

8. Orhii P, Noland K, Rutstein J, Kalu D. Effect of growth hormone therapy on cancellous bone in aged ovariectomized rats. J Bone Miner Res 1996; Suppl 11: S458.

9. Ueland T, Bollerslev J, Hansen TB et al. Increased Cortical Bone Content of Insulin-Like Growth Factors in Acromegalic Patients. J Clin Endocrinol Metab 1999; 84: 123-127.

10. Ogata Y, Niisato N, Sakurai T, Furuyama S, Sugiya H. Comparison of the characteristics of human gingival fibroblasts and periodontal ligament cells. J Periodontol 1995; 66: 1025-1031.

11. Ohgi S, Johnson PW. Glucose modulates growth of gingival fibroblasts and periodontal ligament cells: correlation with expression of basic fibroblast growth factor. J Periodontal Res 1996; 31: 579-588.

12. Kanzaki H, Chiba M, Shimizu Y, Mitani H. Periodontal ligament cells under mechanical stress induce osteoclastogenesis by receptor activator of nuclear factor kappaB ligand up-regulation via prostaglandin E2 synthesis. J Bone Miner Res 2002; 17: 210-220.

13. Kanzaki H, Chiba M, Shimizu Y, Mitani H. Dual regulation of osteoclast differention by periodontal ligament cells through RANKL stimulation and OPG inhibition. J Dent Res 2001; 80: 887-891.

14. Haase HR, Clarkson RW, Waters MJ, Bartold PM. Growth factor modulation of mitogenic responses and proteoglycan synthesis by human periodontal fibroblasts. J Cell Physiol 1998; 174: 353-361.

15. American Academy of Periodontology - Position paper. Parameter on Chronic Periodontitis with Slight to Moderate Loss of Periodontal Support. J Periodontol 2000; Supp1 71: 853-855.

16. American Academy of Periodontology - Position paper. Parameter on Chronic Periodontitis with Advanced Loss of Perodontal Support. J Periodontol 2000; Suppl 71: 856-858.

17. Ainamo J, Bay I. Problems and proposals for recording gingivitis and plaque. Int Dent J 1975; 25: 229-235.

18. Carranza FA. Diagnosis,Prognosis and Treatment Plan.In: Glickman's Clinical Periodontology. W.B Saunders Company 1990; 483-484.
19. Giustina A, Chanson P, Bronstein MD et al. Acromegaly Consensus Group. A Consensus on Criteria for Cure of Acromegaly. J Clin Endocrinol Metab 2010; 95: 3141-3148.

20. Melmed S, Colao A, Barkan A et al. Acromegaly Consensus Group. Guidelines for acromegaly management: an update. J Clin Endocrinol Metab 2009; 94: 1509-1517.

21. Gökalp SG, Dogan BG, Tekcicek MT, Berberoglu A, Unlüer S. National survey of oral health status of children and adults in Turkey. Community Dental Health 2010; 27: 12-17.

22. Kanli A, Kanbur NO, Dural S, Derman O. Effects of Oral Health Behaviors and Socioeconomic factors on a group of Turkish Adolescents Quintessence Int 2008; 39: 88.

23. Saydam G, Oktay I. Periodontal Health Status and Treatment needs for Index age groups in Turkey based on CPITN values. J Nihon Univ. Sch. of Dentistry 2001; 33: 147-151.

24. Gündüz SB, Zvonimir C. Periodontal Condition in Turkish recruits. Comm Dentistry Oral Epidemiol 1976; 4: 25-29.

25. Capoglu I, Yilmaz AB, Ünüvar N, Orbak R, Aksoy H, Yesilyurt H. Gingival enlargement in acromegaly. Endocrine 2002; 18: 207-210.

26. Ionescu O, Sonnet E, Roudaut N, Prédine-Hug F, Kerlan V. Oral manifestations of endocrine dysfunction. Ann Endocrinol (Paris) 2004; 65: 459-465.

27. Waxler R. Acromegaly. Am J Orthod Dentofacial Orthop 2007; $131-$ 136

28. Lima DLP, Montenegro RM, Vieira APGF, Albano MF, Rego DM. Absence of periodontitis in acromegalic patients. Clin Oral Invest 2009; 13: $165-169$.

29. Britto IM, Aguiar-Oliveira MH, Oliveira-Neto LA et al. Periodontal disease in adults with untreated congenital growth hormone deficiency: a case-control study. J Clin Periodontol 2011; 38: 525-531.

30. Oikarinen K, Salo T, Käär ML, Lahtela P, Altonen M. Hereditary gingival fibromatosis associated with growth hormone deficiency. Br J Oral Maxillofac Surg 1990; 28: 335-339.

Received August 22, 2013. Accepted March 5, 2014. 